\title{
REVIEW
}

\section{Expert Opinion: Patient Selection for Premixed Insulin Formulations in Diabetes Care}

\author{
Sanjay Kalra · Leszek Czupryniak · Gary Kilov • Roberta Lamptey • Ajay Kumar • A. G. Unnikrishnan • \\ Aissa Boudiba - Mohamed Abid - Zhanay A. Akanov • Ali Latheef - Mustafa Araz • Ralph Audehm • \\ Silver Bahendeka · Naby Balde $\cdot$ Sandeep Chaudhary $\cdot$ Chaicharn Deerochanawong · Olufemi Fasanmade • \\ Hinde Iraqi · Tint Swe Latt · Jean Claude Mbanya · Joel Rodriguez-Saldana · Ko Seung Hyun · Zafar A. Latif • \\ Maxim Lushchyk · Magdy Megallaa · Mohammed Wali Naseri · Nguyen Quang Bay · Kaushik Ramaiya • \\ Hoosen Randeree · Syed Abbas Raza · Khalid Shaikh • Dina Shrestha · Eugene Sobngwi · Noel Somasundaram • \\ Norlela Sukor · Rima Tan
}

Received: August 29, 2018 / Published online: November 3, 2018

(C) The Author(s) 2018

\section{ABSTRACT}

Premixed insulins are an important tool for glycemic control in persons with diabetes. Equally important in diabetes care is the selection of the most appropriate insulin regimen for

Enhanced digital features To view enhanced digital features for this article go to https://doi.org/10.6084/ m9.figshare.7152554.

\section{S. Kalra $(\bowtie)$}

Department of Endocrinology, Bharti Hospital

Karnal, Karnal, India

e-mail: brideknl@gmail.com

L. Czupryniak

Department of Diabetology and Internal Medicine, Medical University of Warsaw, Warsaw, Poland

\section{G. Kilov · R. Audehm}

Department of General Practice, University of

Melbourne, Melbourne, Australia

R. Lamptey

Department of Family Medicine, Korle Bu Teaching Hospital, University of Ghana, School of Public Health Ghana, Accra, Ghana

\section{A. Kumar}

Department of Diabetology, Diabetes Care and

Research Centre, Patna, India

A. G. Unnikrishnan

Department of Endocrinology, Chellaram Diabetes Institute, Pune, India a particular individual at a specific time. Currently, the choice of insulin regimens for initiation or intensification of therapy is a subjective decision. In this article, we share insights, which will help in rational and objective selection of premixed formulations for initiation and intensification of insulin therapy. The glycemic status and its variations in a person help to identify the most appropriate insulin regimen and formulation for him or her. The evolution of objective glucometric indices has enabled
A. Boudiba
Department of Endocrinology and Diabetology, University Hospital Center Mustapha, Algiers, Algeria
M. Abid
Department of Endocrinology and Diabetology, Hedi Chaker University Hospital, Sfax, Tunisia

\section{Z. A. Akanov}
Center of Diabetes, Clinic of Internal Diseases, Asfendyarov Kazakh National Medical University, Almaty, Republic of Kazakhstan
A. Latheef
Department of Medicine, Indra Gandhi Hospital, Male, Maldives
M. Araz
Department of Endocrinology and Metabolism, Gaziantep University Hospital, Gaziantep, Turkey 
better glycemic monitoring of individuals with diabetes. Management of diabetes has evolved from a 'glucocentric' approach to a 'patientcentered' approach; patient characteristics, needs, and preferences should be evaluated when considering premixed insulin for treatment of diabetes.

Funding: Novo Nordisk, India.

Keywords: BIAsp; Coformulation; IDegAsp; Insulin initiation; Insulin intensification; LisproMix; Patient-centered; Premixed; Type 2 diabetes

\section{INTRODUCTION}

Diabetes is a huge and growing global public health problem with an enormous economic burden [1]. According to the International Diabetes Federation (IDF), the number of adults living with diabetes in 2017 is projected to increase from 425 to 629 million in 2045 (a 48\% rise) [2]. The loss of the first phase of insulin is the initial pathophysiologic defect in type 2 diabetes mellitus [3]. Insulin, alone or along with other pharmacologic and nonpharmacologic measures of treatment, is widely used in

\author{
S. Bahendeka \\ Department of Diabetology, St. Francis Hospital, \\ Nsambya, Uganda \\ N. Balde \\ Department of Endocrinology, Donka Conakry \\ University Hospital, Conakry, Guinea \\ S. Chaudhary \\ Department of Endocrinology, NMC Speciality \\ Hospital, Dubai, United Arab Emirates \\ C. Deerochanawong \\ Diabetes and Endocrinology Unit, College of \\ Medicine, Rangsit University, Rajavithi Hospital, \\ Bangkok, Thailand \\ O. Fasanmade \\ Department of Endocrinology, Lagos University \\ Teaching Hospital, Lagos, Nigeria \\ H. Iraqi \\ Department of Endocrinology and Diabetology, \\ Faculty of Medicine and Pharmacie, Mohammed V \\ University, Rabat, Morocco
}

the management of diabetes. Insulin enables adequate glycemic control thus significantly reducing the vascular complications of diabetes. Early insulin use has been associated with reversal of diabetes [4-6].

To tackle the epidemic of diabetes, various countries are scaling up equitable and affordable access to insulin for improved care [2]. Multiple regimens, formulations, and delivery devices of insulin are increasingly being used to individualize treatment and attain the best possible glycemic control in people with diabetes $[7,8]$. Available subcutaneous insulins differ in onset, peak, and duration of action and in safety profiles, ranging from ultra-short-acting to ultralong-acting preparations. With a plethora of formulations, which need to be matched with heterogenous patient profiles, the initiation and intensification of insulin therapy are increasingly becoming challenging [8]. Adult-onset diabetes has been stratified into subgroups to individualize treatment according to patient characteristics, disease progression, and risk of diabetic complications. These subgroups include insulin-deficient and insulin-resistant diabetes as well as mild obesity- and age-related diabetes [9].

Guidelines for the non-pharmacologic and pharmacologic management of diabetes have

T. S. Latt

Myanmar Diabetes Association, Yangon, Myanmar

J. C. Mbanya · E. Sobngwi

Department of Internal Medicine, Central Hospital, Yaoundé, Cameroon

J. Rodriguez-Saldana

Multidisciplinario de Diabetes Centre, Mexico City, Mexico

K. S. Hyun

Department of Endocrinology, St Vincent's

Hospital, Catholic University, Suwon, South Korea

Z. A. Latif

BIRDEM, Dhaka, Bangladesh

M. Lushchyk

Department of Endocrinology, Belarusian Medical Academy of Postgraduate Education, Minsk, Belarus

M. Megallaa

Department of Diabetes and Metabolism, Alexandria University, Alexandria, Egypt 
been formulated by the IDF, American Diabetes Association (ADA), and American Association of Clinical Endocrinologists (AACE) and American College of Endocrinology (ACE). The approach to insulin therapy has been described in multiple guidelines for diabetes. The ADA has described an algorithm for the initiation of insulin therapy with basal insulin and the stepwise inclusion of rapid-acting and premixed insulins [10]. The IDF and AACE/ACE have also described a comprehensive algorithm for adding or intensifying insulin in persons with type 2 diabetes $[2,11]$. The AACE/ACE explores factors that should be considered when selecting a formulation for insulin initiation, including age, life expectancy, motivation, presence of complications, overall health status, and cost of formulations. In these guidelines, the key disease characteristics influencing the choice for initiation and continuation of therapy include the duration and severity of diabetes. Though these guidelines provide elaborate algorithms for insulin therapy, criteria for regimen and formulation selection are inadequately addressed. The guidelines, which largely focused on basal and rapid-acting insulins, do not include directions for use of all available formulations.

The East African Diabetes Study Group (EADSG) Guidelines recommend that insulin

\section{W. Naseri}

Department of Internal Medicine, Division of Endocrinology, Metabolism and Diabetes, Kabul University of Medical Sciences, Kabul, Afghanistan

\section{N. Q. Bay}

Department of Endocrinology, Bach Mai Hospital, Hanoi, Vietnam

\section{K. Ramaiya}

Department of Diabetology, Shree Hindu Mandal Hospital, Dar es Salaam, Tanzania

H. Randeree

Department of Endocrinology, Parklands Medical Centre, Durban, South Africa

\section{S. A. Raza}

Department of Endocrinology, Shaukat Khanum Memorial Cancer Hospital and Research Centre, Lahore, Pakistan

K. Shaikh

Department of Endocrinology, Royal Oman Police Hospital, Muscat, Oman therapy in people with diabetes should not be delayed and patients should be educated about insulin regimens, choice of formulations for treatment, and regular monitoring of glycemic control [12]. These guidelines together with those of the Research Society for the Study of Diabetes in India (RSSDI) [13] and the Society for Endocrinology, Metabolism and Diabetes of South Africa [14] have explained practical aspects of insulin regimens in detail, providing a patient-centered approach to initiation and intensification of therapy.

There are some guidelines that provide directions for the initiation and intensification of insulin therapy with premixed insulin [15-20]. However, these guidelines do not compare the premixed insulin preparations with other insulin preparations. In addition, these guidelines do not specifically describe the patient characteristics that prompt a preference for premixed insulins. In this article, we identify the gaps in current practices and build an objective, rational approach to patient selection for premixed insulins. This article is based on previously conducted studies and does not involve any new studies of human or animal subjects performed by any of the authors.

\section{Shrestha}

Department of Endocrinology, Norvic International Hospital, Kathmandu, Nepal

\author{
N. Somasundaram \\ Department of Diabetes and Endocrinology, \\ National Hospital of Sri Lanka, Colombo, Sri Lanka \\ N. Sukor \\ Endocrine Unit, Department of Medicine, National \\ University of Malaysia Medical Center, Kuala \\ Lumpur, Malaysia \\ R. Tan \\ Institute for Studies on Diabetes Foundation Inc, \\ Marikina City, Philippines
}


Table 1 Formulations of premixed insulin

\begin{tabular}{|c|c|c|c|}
\hline $\begin{array}{l}\text { Type of premixed } \\
\text { insulin }\end{array}$ & Low-mix formulations & Mid-mix formulations & High-mix formulations \\
\hline $\begin{array}{l}\text { Premixed regular } \\
\text { insulin-NPH }\end{array}$ & $\begin{array}{l}30 \% \text { insulin regular } / 70 \% \text { insulin } \\
\mathrm{NPH}\end{array}$ & $\begin{array}{l}50 \% \text { insulin regular } / 50 \% \text { insulin } \\
\mathrm{NPH}\end{array}$ & $\begin{array}{l}\text { Biphasic human insulin } 75 \\
75 \% \text { insulin regular/25\% } \\
\text { insulin NPH }\end{array}$ \\
\hline \multirow[t]{2}{*}{$\begin{array}{l}\text { Premixed insulin } \\
\text { analogs }\end{array}$} & $\begin{array}{l}30 \% \text { insulin aspart } / 70 \% \text { insulin } \\
\text { aspart protamine }\end{array}$ & $\begin{array}{l}50 \% \text { insulin lispro/50\% insulin } \\
\text { lispro protamine }\end{array}$ & $\begin{array}{l}\text { Biphasic human lispro } 75 \\
\text { Biphasic human lispro } 70\end{array}$ \\
\hline & $\begin{array}{l}25 \% \text { insulin lispro/75\% insulin } \\
\text { lispro protamine }\end{array}$ & $\begin{array}{l}50 \% \text { insulin aspart } / 50 \% \text { insulin } \\
\text { aspart protamine }\end{array}$ & Biphasic human aspart 70 \\
\hline Coformulation & $\begin{array}{l}70 \% \text { insulin degludec } / 30 \% \text { insulin } \\
\text { aspart }\end{array}$ & & \\
\hline
\end{tabular}

$\mathrm{NPH}$ neutral protamine Hagedorn

\section{PREMIXED INSULIN: FORMULATIONS AND PHARMACOKINETICS}

Premixed insulins are fixed component formulations of rapid or short-acting and intermediate- or long-acting insulins for both fasting and postprandial glycemic control. These formulations include the conventional premixed formulations with human insulin, premixed analog formulations, and a premixed coformulation of rapid-acting and ultra-long-acting basal insulin analogs $[12,21]$ (Table 1). Premixed insulins can be dosed once, twice, or thrice daily, depending upon patient requirements.

The premixed insulins have pharmacokinetics that favor both 24-h efficacy and patient convenience. This explains the high adherence rates and better glycemic control with premixed insulins [12]. The conventional premixed biphasic human insulin is a combination of regular human insulin and neutral protamine Hagedorn (NPH) in ratios of $30 / 70$ or $50 / 50$. These are administered $30 \mathrm{~min}$ prior to meals, and the action lasts for about 10-16 h. The analog premixed formulations (Lispro 25/75, Lispro 50/50, BIAsp 30/70, BIAsp 50/50) have a quicker onset of action and can be administered up to $15 \mathrm{~min}$ prior to meals. When compared with conventional premixed formulations, the analog formulations are longer acting with duration of action ranging from 12 to $24 \mathrm{~h}$.

IDegAsp (70/30) is a combination of the ultra-long-acting insulin degludec (IDeg) and rapid-acting analog insulin aspart (IAsp) that provides safe and well-tolerated control of both fasting and prandial hyperglycemia [22]. IDegAsp 70/30 offers advantages of mealtime flexibility with quicker onset (10-20 min) and longer duration of action $(>24 \mathrm{~h})[12,21,23]$.

\section{PREMIXED INSULIN: INITIATION AND INTENSIFICATION}

Premixed insulin analogs have efficacy and safety outcomes similar to those of basal or basal-bolus insulin [24, 25]. In a review comparing premixed and basal plus regimens, Downie et al. reported similar efficacy and safety with both regimens for both insulin initiation in insulin-naive patients and intensification in patients who have failed on basal insulin [26]. In a meta-analysis of 13 randomized controlled trials (16-60 weeks; $n=5255$ ) comparing the premixed and basal-bolus regimens, there were no significant differences in HbA1c levels, rate of hypoglycemia, weight change, or daily insulin dose with the two regimens despite the greater complexity and 
number of injections associated with basal-bolus insulin [27]. Better overall glycemic control is also reported with premixed insulins (insulin lispro 25/27; BIAsp 70/30) than with the basal insulins (insulin glargine) in insulin-naïve as well as pretreated patients [28, 29]. Some researchers report a higher risk of minor nocturnal hypoglycemia with premixed insulin than with basal insulin regimen [30].

The Indian National Consensus Group (INCG) has provided guidance for initiation and intensification of therapy with premixed insulin in the management of diabetes in primary care [31]. According to INCG, premixed insulins, preferably analog formulations, offer a simple, safe, and easy option for the initiation of treatment in diabetes and should be considered for the management of all stages of diabetes. The Royal Australian College of General Practitioners (RACGP) and RSSDI has provided guidance for the initiation, titration, and intensification of therapy with premixed insulin. According to these guidelines, premixed insulin may be an appropriate and simple option for glycemic control when fasting and postprandial glucose levels are consistently elevated. Patients may be switched to premixed insulin if target HbA1c levels are not achieved with basal insulin alone or therapy intensified to basal plus or basal bolus. It is important to emphasize appropriate nutrition and physical activity at all stages of treatment initiation and intensification.

Treatment with premixed insulin (10 $\mathrm{U}$ or $0.1-0.2 \mathrm{U} / \mathrm{kg} /$ day immediately before or soon after the largest meal, usually the evening meal) can be started in insulin-naïve persons with diabetes. The dose is then titrated once or twice a week depending upon the lowest blood glucose levels (fasting/prandial) over the last 3 days. Asians with lower BMI may require a lower dose. The once daily dose may be equally split into a pre-breakfast and pre-dinner dose if the evening preprandial glucose levels or HbA1c remain high or if dose requirements increase beyond $30 \mathrm{U} /$ day or $0.4 \mathrm{U} / \mathrm{kg} /$ day. Some clinicians use the criteria of $50 \mathrm{U} /$ day or 0.5 $\mathrm{U} / \mathrm{kg} /$ day to guide the twice daily dosing of premixed insulin. Twice daily dosing can again be titrated to achieve the target fasting and prandial glycemic control $[13,17]$. A practical approach commonly used for high-mix insulin is to distribute the dose of premixed insulin as two-thirds in the morning and one-third in the evening when the once-daily insulin dose exceeds 20 or $30 \mathrm{U}$.

\section{FACTORS INFLUENCING CHOICE OF PREMIXED FORMULATIONS}

\section{Patient-Centered/Subjective Factors}

Glycemic control is determined not only by insulin formulations, but also by patient characteristics $[9,26]$. Few guidelines have elaborated upon patient characteristics to guide the choice for initiation and intensification of therapy with premixed insulin. The RACGP lists patient characteristics that should be considered for initiating and planning insulin treatment. These include the physical and cognitive capability to administer multiple injections and monitor blood glucose several times a day, support of the family and treating physician, patient preferences, meal patterns, and activity routine [17].

The key patient characteristics that influence the choice of therapy with premixed insulin include duration and symptoms of hyperglycemia, overall health and other medical conditions, past and ongoing treatment, lifestyle, and patient preferences (Table 2). An appropriate history, detailed physical examination, and required investigations can help to adopt a patient-centered approach in tailoring treatment with premixed insulin.

Patients should be engaged in decision making when selecting an insulin formulation for glycemic control [32]. Patients should be encouraged to adopt consistent meal timings and components. They should also be asked for preference regarding injection frequency and blood glucose monitoring. In addition, costs should be discussed to make the therapy affordable in the long term [33]. Continuous support and guidance from the treating physician can help combat patient fears and doubts and reduce the possibility of 'psychological insulin resistance' $[34,35]$. Initial and 
Table 2 Patient selection for premixed insulin

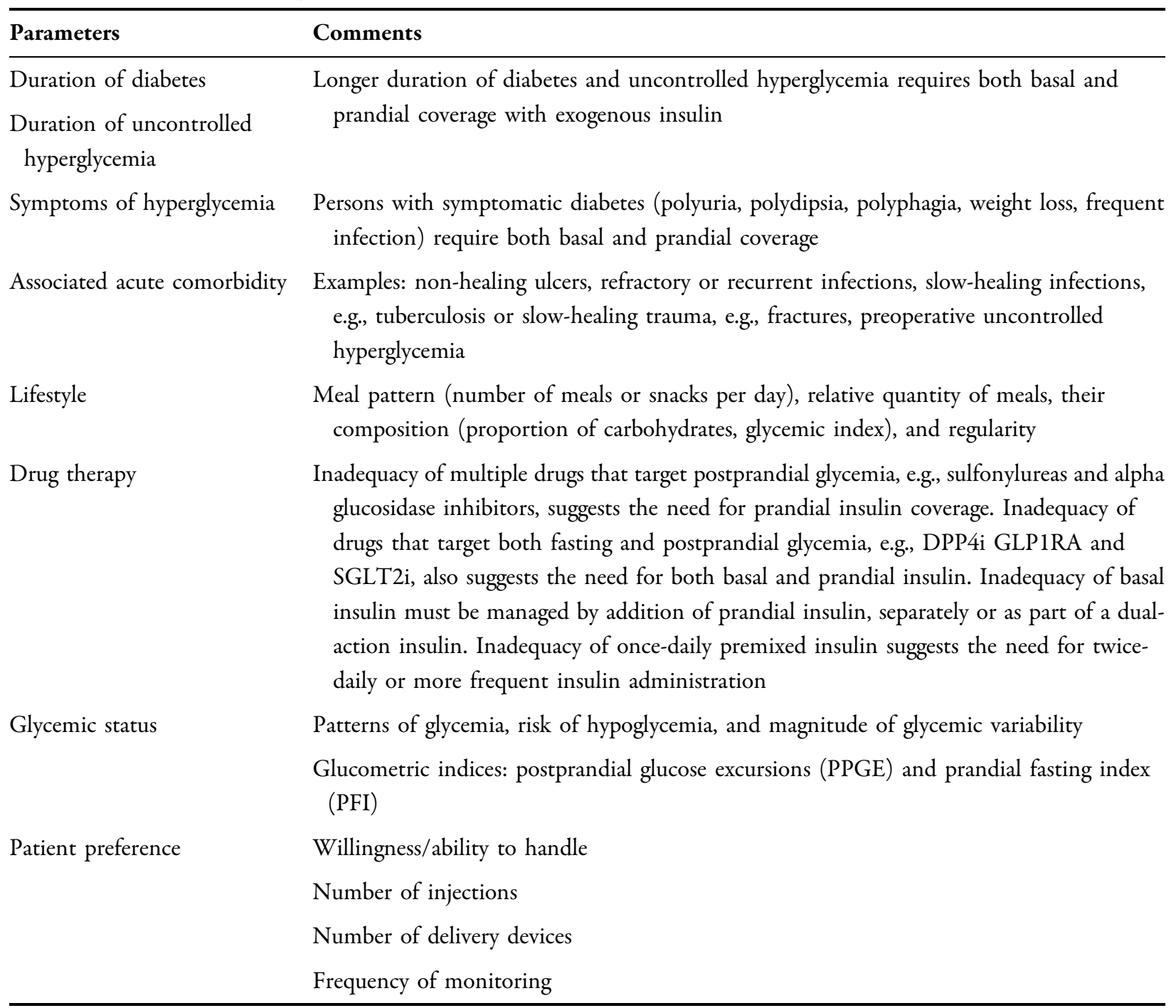

APP Alc prandial product, $P F I$ prandial fasting index, $P P G E$ postprandial glucose excursions

continued therapy with premixed insulin should be guided by patient attributes and tailored to patient needs instead of trying to find a 'one-size-fits-all' regimen. Initiation of a small dose of insulin (2 IU) in the clinic helps to overcome needle phobia.

\section{Dietary Factors}

Dietary patterns and preferences influence glycemic control and are an important factor to be considered in the selection of insulin formulations for treatment.
Dietary composition: premixed insulins are best used in persons who consume meals of balanced and uniform dietary composition. The EADSG Guidelines emphasize the importance of matching the dose of insulin to carbohydrate intake [12]. The INCG recommends only premixed insulin at initiation as high glycemic levels in response to a meal are more common in ethnic Asian communities [36]. There may also be racial variations in the physiologic glycemic response to meals [37]. Asians have relatively higher post-prandial glucose levels due to consumption of carbohydrate-rich diets. The diets of West Africans are rich in carbohydrates, 
and hence post-prandial glucose levels tend to be high. Premixed insulins are the preferred preparation in the Southeast Asian and African countries and are included in the National List of Essential Medicines of various countries [22].

Dietary patterns: regularity in meals is key in the achievement of glycemic goals. However, dietary patterns may vary according to professional lifestyles and religious practices. Cultural practices such as Ramadan influence the glycemic control and use of insulin in people with diabetes [21]. Premixed insulin analogs with an established efficacy and safety profile and lower rates of hypoglycemia are preferred over premixed human insulins in people with diabetes during periods of religious fasting. IDegAsp may be considered as the preferred premixed insulin for people with diabetes who fast during Ramadan. Risk stratification and counseling are important in these individuals. Persons with erratic dietary patterns may benefit from IDeg Asp as it does not need to be injected at the same meal time(s) each day.

\section{Lifestyle}

In patients with busy/stressful lifestyles and erratic meal patterns, the flexibility to match insulin administration with the major meal of the day offers convenience and improves compliance. According to a multinational consensus group, IDegAsp is a good preparation for initiation of insulin therapy in the following: drug-naive patients with symptoms of hyperglycemia, patients on a high carbohydrate diet, patients with high HbA1c levels, and postprandial excursions. It can also be used to initiate therapy following failure of (single, dual, or triple) oral anti-diabeteic agents [38].

\section{Overall Health Status}

The overall health of the patient is a key determinant for the choice of insulin formulation. Analogs have an advantage over human insulins due to the lower risk of hypoglycemia associated with their use [29].

\section{Metabolic Health}

Another important determinant of glycemic goals and control is the metabolic health of the patient. This includes non-glycemic parameters related to renal, hepatic, endocrine, and metabolic parameters. The Metabolic Quartet, HbA1c, blood pressure, weight, and lipids, describes the four vasculo-metabolic targets in diabetic patients [39]. The pathology of postprandial hyperglycemia may include impaired glucagon suppression in addition to reduced secretion of insulin [40].

\section{Number of Injections/Day}

A number-based insulin taxonomic model has been developed to offer a more patient-centric care for diabetes [41]. This model, based on variables such as the number of injections per day and the pharmacokinetic and pharmacodynamic characteristics of insulin preparations, helps inform the choice of therapy with available formulations of insulin. This model reflects the versatility of insulin in the management of diabetes and enables the physician to choose a formulation according to patient needs. The model assigns a code based on the frequency of injections and simplifies the classification of regimens used for insulin therapy including the premixed insulins. Based upon the patterns of an individual's glycemic levels, motivation level, psychosocial limitations, ease of use, and acceptance of insulin, premixed insulin can be used once, twice, or thrice daily.

\section{Patient Preferences}

Premixed insulin is the best option in patients who are unwilling or unable to adhere to the increased injections and monitoring required with basal plus/basal-bolus regimens [42]. As a patient-centered approach to the management of diabetes, patient-reported outcomes (PROs) should be measured before and during treatment. Quality of life is a common measurable target that can be used to determine the outcomes of insulin regimens. Other potential PROs include patient satisfaction, diabetes distress, anxiety and depression, coping skills, and communication [39].

\section{Patient Satisfaction and Convenience}

Patient satisfaction is important for the initiation and continuation of insulin therapy. 
Patients on basal-bolus or basal plus insulin may show dissatisfaction with therapy due to the excessive variability in glycemic levels, frequent episodes of nocturnal hypoglycemia, and multiple injections [23].

Where fewer injections are required, flexibility in time of administration, and reduction of the injection-meal time gap, IDegAsp insulin offers more convenience to patients. Twice daily premixed insulin regimens protect the privacy of a patient and allow freedom of choice in self-disclosure of medical status. The flexibility in timing of administration makes this premixed co-formulation a preferred choice, particularly for people with busy lifestyles and variable meal patterns [43].

\section{Insulin Distress}

Defined as the emotional response to the suggestion of insulin use, insulin distress is a common deterrent in attainment of glycemic control. Premixed insulins having a lower index of intrusion and flexibility help to reduce insulin distress [44]. Patient distress, apprehension, and anxiety associated with insulin use are reduced if such formulations are used. The pharmacokinetics of premixed insulin allow a more patient-friendly approach to initiation and continuation of therapy.

\section{Laws of Parsimony}

Premixed insulins enable the adoption of the Law of Therapeutic Parsimony in diabetes care. According to this law, the least number, quantity, and frequency of administration of a drug should be prescribed to achieve desired therapeutic outcomes without compromising the safety and well-being of patients [45]. With control of both fasting and prandial glucose levels and HbA1c, premixed insulins are an appropriate choice for achieving glycemic targets and reducing complications in persons with diabetes. The use of premixed formulations has allowed a reduction in numbers of required injections. The flexibility offered by premixed analogs is associated with reduction in injection-meal time gaps and improved compliance. These formulations have reduced the requirement for frequent glucose monitoring.

\section{Gluco-Centric/Objective Parameters}

Many subjective parameters guide the choice of formulation and regimen in therapy with premixed insulins. There is a need to include more objective parameters of patient characteristics to enable the selection of 'right insulin for the right person.'

Premixed insulin formulations can be combined with bolus insulins to customize the insulin regimens to suit individual glycemic profiles and patient needs in diabetics [41]. In patients with severe insulin deficiency or resistance, IDegAsp may be administered with the main meal and IAsp may be administered with the other two meals to build a three-dose intensive regimen for achieving glycemic targets [23].

\section{Glycemic Status}

In individuals with diabetes, the glycemic status is influenced by several clinical and biochemical factors (Fig. 1). Changes in glycemic status, determined by history, clinical examination, and glucometric indices, help to determine the etiology and pathogenesis of dysglycemia and plan the appropriate therapeutic strategies (Tables 1, 2) [49]. Glycemic status may be classified as predominant insulin deficiency or insulin resistance and predominant fasting, prandial, or combined hyperglycemia. Obesity and other modifiable factors may impact the glycemic status of an individual [46-48]. Reinforcing the patient-centered approach suggested by guidelines [16], the determination and monitoring of glycemic status can help to translate glycemic management into better patient outcomes.

\section{Glycemic Variations}

Glycemic variations including predominant fasting hyperglycemia, predominant postprandial hyperglycemia, overall hyperglycemia, risk of hypoglycemia, and comorbidities should be determined to guide the choice of therapy in diabetics. The quantity, composition, and 


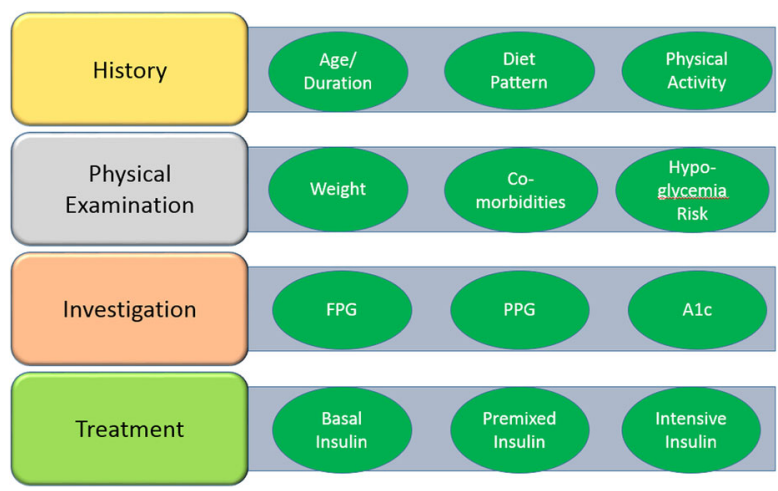

Fig. 1 Factors influencing glycemic status in individuals with diabetes

patterns of dietary intake are a key determinant of glycemic variations in individuals with diabetes. Another equally important factor is lifestyle, which includes the duration, intensity, and patterns of physical activity. Persons on premixed insulin should be counseled not to indulge in unaccustomed vigorous physical activity within $2-3 \mathrm{~h}$ of taking the injection. Comorbid conditions such as rheumatoid arthritis, asthma, acromegaly, hyperthyroidism, and Cushing's syndrome may worsen hyperglycemia, while diseases such as hypothyroidism, Addison's disease, renal and hepatic impairment, and malabsorption syndromes, such as celiac disease, may precipitate hypoglycemia. Further, complications associated with diabetes may amplify challenges in glycemic control. Variability in glucose levels may be seen in conditions such as diabetic gastroparesis. These factors necessitate glycemic monitoring in people with diabetes to achieve glycemic targets while reducing glucose variability and hypoglycemia.

There are some situations in which a basal bolus regimen may be preferred. Usually, these are persons with type 1 diabetes or life-, organ-, or limb-threatening complications. These include persons with LADA, pancreatic diabetes, brittle diabetes, gestational diabetes mellitus, and new onset diabetes after transplant (NODAT). These situations also include persons with diseases such as tuberculosis, extensive foot ulcer, or other severe infections.
In patients with both fasting and postprandial high glucose levels, it may be useful to determine the predominant hyperglycemia. A person with predominant fasting hyperglycemia may require either basal insulin at bedtime or one premixed injection before dinner [43], while another with postprandial hyperglycemia will respond to a breakfast dose. High glycemic levels throughout the day will warrant a two- or three-dose premixed regimen. Dietary patterns influence the glycemic variations and prescription of a number of doses of premixed insulin. Persons who consume very high carbohydrate meals will respond better to high-mix formulations, while those who are at high risk of hypoglycemia may prefer low-mix formulations, especially analogs.

\section{Glucometric Indices}

The evolution of objective glucometric indices has provided a better understanding of glycemic control [32]. Both fasting and postprandial levels of glycemia are components in determining the HbA1c levels. The most common indices for glycemic control include fasting and postprandial glucose levels and HbA1c. These together make the glycemic triad. These parameters together with minimum glycemic variability and minimum hypoglycemia make the glycemic tetrad and pentad, respectively [49].

Various glucometric indices such as postprandial glucose excursions (PPGE) and the prandial fasting index (PFI) have been suggested to bring objectivity to the choice of therapy (Table 3) [32]. These indices help to determine the relative contribution of fasting and postprandial glucose levels to hyperglycemia. While these indices are not validated, they serve as a useful therapeutic framework to allow use of insulin in a rational manner. High PPGE and PFI suggest a higher postprandial glycemic burden. Another validated index calculated as the ratio of the fasting blood glucose levels and HbA1c index serves as an indicator of the contribution of fasting hyperglycemia to the glycemic burden [32]. When compared with the ratio of fasting blood glucose levels and HbA1c, PPGE and PFI are cheaper alternatives and are more affordable [32]. These indices can serve as useful 
Table 3 Glucometric indices and choice of insulin

\begin{tabular}{lll}
\hline Indices & Prefer premix $^{\mathbf{a}}$ & Prefer basal $^{\mathbf{a}}$ \\
\hline PPGE $=$ PPG - FPG & $40-74 \mathrm{mg} / \mathrm{dl}$ & $<40 \mathrm{mg} / \mathrm{dl}$ \\
& $2.2-4.1 \mathrm{mmol} / 1$ & $<2.2 \mathrm{mmol} / \mathrm{l}$ \\
$\mathrm{PFI}=\frac{\mathrm{PPG}-\mathrm{FPG}}{\mathrm{FPG}}$ & $0.4-0.6$ & $<0.4$ \\
$\mathrm{FPG} / \mathrm{HbAlc}{ }^{\mathrm{b}}$ & $\leq 20$ & $\geq 20$ \\
\hline
\end{tabular}

$F P G$ fasting plasma glucose, $P P G$ postprandial plasma glucose, $P P G E$ postprandial glucose excursion, PFI prandial fasting index

a The cutoff values are arbitrary and are based upon diagnostic values for prediabetes and diabetes. For derivation, refer to Kalra [32]

b Using FPG $(126 \mathrm{mg} / \mathrm{dl})$ and currently accepted HbAlc (6.3\%) levels

clinical decision-making tools in diabetes care. The indices should be validated in clinical studies for informed and widespread application in diabetes management.

\section{SUMMARY}

Premixed insulins have unique pharmacokinetic profiles and established efficacy for glycemic control, which enables multiple and safe dosing in persons with diabetes. However, there is insufficient guidance on how to choose one insulin formulation over another. Patient characteristics are key in selecting the right formulation of premixed insulin in the management of diabetes. Dietary patterns, overall and glycemic health, comorbid conditions, and any antidiabetic and other concomitant medications influence the selection and continuation of premixed insulin therapy (Table 4). Insulin stewardship programs in healthcare settings can help make a pragmatic choice of formulation, initiate and manage appropriate dosing, provide guidance on handling, storage, and disposal of insulin preparations, enable periodic monitoring, and formulate policies for physician and patient education.

When compared with premixed human insulin, premixed analog insulins offer a better mealtime flexibility, postprandial glycemic control, hypoglycemic profile, weight management, and comparable fasting glucose control $[12,36]$. IDegAsp may be preferred over premixed insulin analogs because of the potentially lower incidence of overall and nocturnal hypoglycemia and superior fasting glycemic control $[21,40]$. However, cost may be a limiting factor, and some countries may not have access to IDegAsp.

Most guidelines suggest intensification of insulin regimens with basal-bolus or premixed analogs. However, these guidelines do not provide guidance for the choice of ratio in premixed formulations $(30 / 70,50 / 50$, or $70 / 30)$ $[2,10,11,16,17]$. Choice of a premixed formulation should be individualized based upon glycemic patterns (Table 4). Different formulations may be used together, for example, a midmix (50/50) formulation may be given before breakfast and a low-mix (30/70) formulation may be given before dinner to provide more overnight basal insulin. Low-mix formulations may be switched to mid-mix formulations for dosing before a meal that routinely has the highest carbohydrate content or one that has high (>10 mmol/l) 2-h postprandial glucose levels [50]. When compared with low-mix formulations, mid-mix insulins offer better control of post-prandial glycemia, lesser glucose excursions, and less intense self-monitoring of blood glucose levels. However, few studies have reported significant reductions in $\mathrm{HbA1c}$ with the initiation [51, 52] and intensification [53] of therapy with mid-mix formulations compared with low-mix formulations.

Individuals with diabetes have heterogenous patient characteristics and glycemic profiles. The current article describes a rational approach to patient selection for premixed insulin therapy. It is concordant with the classic hierarchy (history, clinical examination, and investigations) followed in medical practice (Table 2). This article reinforces the importance of glycemic status and its variations and reviews the glucometric indices that can be used to objectively plan and execute treatment with premixed insulins. Objectivity in glycemic monitoring can help to select the right formulation of premixed insulin for the right patient. Dose titration and monitoring are not in the scope of this article and have not been 
Table 4 Type 2 diabetes: Exemplars for initiation/intensification with premixed insulin analogs

\begin{tabular}{|c|c|c|c|c|}
\hline Current therapy & Current medical status & Current glycemic status & Dietary pattern & Intervention \\
\hline $\begin{array}{l}\text { Monotherapy } \\
\text { OAD }\end{array}$ & $\begin{array}{l}\text { Symptoms of } \\
\text { hyperglycemia/catabolism/asthenia } \\
\text { Acute medical or surgical comorbidity } \\
\text { requiring timely resolution of } \\
\text { hyperglycemia }\end{array}$ & $\begin{array}{l}\text { Inadequate } \\
\text { fasting }+ \text { postprandial } \\
\text { control }\end{array}$ & Regular meals & $\begin{array}{l}\text { Initiation with } \\
\text { premixed insulin, } \\
\text { preferably twice } \\
\text { daily }\end{array}$ \\
\hline $\begin{array}{l}\text { OAD, dual or } \\
\text { triple } \\
\text { combination }\end{array}$ & $\begin{array}{l}\text { Symptoms of } \\
\text { hyperglycemia/catabolism/asthenia } \\
\text { Acute medical or surgical comorbidity } \\
\text { requiring timely resolution of } \\
\text { hyperglycemia } \\
\text { Asymptomatic persons }\end{array}$ & $\begin{array}{l}\text { Inadequate } \\
\text { fasting }+ \text { postprandial } \\
\text { control }\end{array}$ & Two heavy meals & $\begin{array}{l}\text { Initiation with } \\
\text { premixed insulin } \\
\text { once daily } \\
\text { Initiation with } \\
\text { premixed insulin } \\
\text { twice daily }\end{array}$ \\
\hline $\begin{array}{l}\text { Basal } \\
\quad \text { insulin + OADs }\end{array}$ & $\begin{array}{l}\text { Symptoms of } \\
\text { hyperglycemia/catabolism/asthenia } \\
\text { Acute medical or surgical comorbidity } \\
\text { requiring timely resolution of } \\
\text { hyperglycemia } \\
\text { Asymptomatic persons }\end{array}$ & $\begin{array}{l}\text { High } \mathrm{HbAlc} \text { inspite of } \\
\text { adequate FPG control } \\
\text { High PPG, } \\
\text { unacceptable nocturnal } \\
\text { hypoglycemia }\end{array}$ & Two heavy meals & $\begin{array}{l}\text { Intensification to } \\
\text { premixed insulin } \\
\text { once daily } \\
\text { Intensification to } \\
\text { premixed insulin } \\
\text { twice daily }\end{array}$ \\
\hline $\begin{array}{l}\text { Premixed insulin } \\
\text { once } \\
\text { daily + OADs }\end{array}$ & $\begin{array}{l}\text { Symptoms of } \\
\text { hyperglycemia/catabolism/asthenia } \\
\text { Acute medical or surgical comorbidity } \\
\text { requiring timely resolution of } \\
\text { hyperglycemia } \\
\text { Asymptomatic persons }\end{array}$ & $\begin{array}{l}\text { High } \mathrm{HbAlc} \text { inspite of } \\
\text { adequate FPG control } \\
\text { High PPG, } \\
\text { unacceptable nocturnal } \\
\text { hypoglycemia }\end{array}$ & Heavy meals & $\begin{array}{l}\text { Intensification to } \\
\text { premixed insulin } \\
\text { twice daily }\end{array}$ \\
\hline \multirow[t]{2}{*}{$\begin{array}{l}\text { Premixed insulin } \\
\text { twice } \\
\text { daily + OADs }\end{array}$} & $\begin{array}{l}\text { Symptoms of } \\
\text { hyperglycemia/catabolism/asthenia } \\
\text { Acute medical or surgical comorbidity } \\
\text { requiring timely resolution of } \\
\text { hyperglycemia }\end{array}$ & $\begin{array}{l}\text { High HbAlc despite adequate } \\
\text { FPG control } \\
\text { High PPG, } \\
\text { unacceptable nocturnal } \\
\text { hypoglycemia }\end{array}$ & Heavy meals & $\begin{array}{l}\text { Intensification to } \\
\text { high mix insulin } \\
\text { Heteromix insulin }^{\mathrm{a}}\end{array}$ \\
\hline & Asymptomatic persons & Post-lunch hyperglycemia & $\begin{array}{l}\text { Three heavy } \\
\text { meals }\end{array}$ & $\begin{array}{l}\text { Intensification to } \\
\text { premixed insulin } \\
\text { thrice daily }\end{array}$ \\
\hline
\end{tabular}

$F P G$ fasting plasma glucose, $O A D$ oral antidiabetic drugs, $P P G$ postprandial glucose

${ }^{a}$ Hetero-mix: One premix combination with the morning meal and a different premix combination with the evening meal. Example: biphasic insulin aspart high-mix (50/50) before breakfast and lunch along with biphasic insulin aspart (30:70) with dinner

discussed. This article should be considered as an addition or complementary to existing guidelines and consensus reports and not as a substitute for them.

Objective selection and matching of patient and formulation, by determination of glycemic status through use of glucometric indices, help maximize the benefit of insulin therapy. Premixed insulin therapy should be chosen as per an individual's characteristics, initiated in a timely manner, monitored regularly, titrated and intensified as needed [43].

\section{ACKNOWLEDGEMENTS}

Funding. This review was funded by Novo Nordisk, India. No article processing charges 
were received by the journal for the publication of this article.

\section{Medical Writing and Editorial Assis-} tance. Medical writing and editorial support in the preparation of this article were provided by Dr. Tarveen Jandoo and Dr. Punit Srivastava of MediCeption Science. Support for this assistance was funded by Novo Nordisk, India.

Authorship. All named authors meet the International Committee of Medical Journal Editors (ICMJE) criteria for authorship for this manuscript, take responsibility for the integrity of the work, and have given final approval for the version to be published.

Disclosures. Sanjay Kalra has received honoraria for providing medical education or working on advisory boards for Novo Nordisk, Lilly and Sanofi. Gary Kilov has received honoraria for providing medical education or working on advisory boards for Novo Nordisk, Lilly and Sanofi. Hinde Iraqi has received honoraria for providing medical education or working on advisory boards for Novo Nordisk, Lilly and Sanofi. Abbas Raza has received honoraria for providing medical education or working on advisory boards for Novo Nordisk, Lilly and Sanofi. Mohamed Abid has received honoraria for providing medical education or working on advisory boards for Novo Nordisk and Sanofi. Roberta Lamptey has received honoraria for providing medical education or working on advisory boards for Novo Nordisk and Sanofi. Olufemi Fasanmade has received honoraria for providing medical education or working on advisory boards for Novo Nordisk and Sanofi. Khalid Shaikh has received honoraria for providing medical education or working on advisory boards for Sanofi and Eli Lilly. Eli Lilly, Novo Nordisk, and Sanofi have provided funding to Jean Claude Mbanya or to institutions with which he is associated for educational, advisory and research activities. All remaining authors (Leszek Czupryniak, Ajay Kumar, A.G. Unnikrishnan, Aissa Boudiba, Zhanay A. Akanov, Ali Latheef, Mustafa Araz, Ralph Audehm, Silver Bahendeka, Naby Balde, Sandeep Chaudhary, Chaicharn Deerochanawong, Tint Swe
Latt, Joel Rodriguez-Saldana, Ko Seung Hyun, Zafar A. Latif, Maxim Lushchyk, Magdy Megallaa, Mohammed Wali Naseri, Nguyen Quang Bay, Kaushik Ramaiya, Hoosen Randeree, Dina Shrestha, Eugene Sobngwi, Noel Somasundaram, Norlela Sukor and Rima Tan) have nothing to disclose.

Compliance with Ethics Guidelines. This article is based on previously conducted studies and does not involve any new studies of human or animal subjects performed by any of the authors.

Open Access. This article is distributed under the terms of the Creative Commons Attribution-NonCommercial 4.0 International License (http://creativecommons.org/licenses/ by-nc/4.0/), which permits any noncommercial use, distribution, and reproduction in any medium, provided you give appropriate credit to the original author(s) and the source, provide a link to the Creative Commons license, and indicate if changes were made.

\section{REFERENCES}

1. World Health Organization. Global report on diabetes. 2018. http://apps.who.int/iris/bitstream/ handle/10665/204871/9789241565257_eng.pdf;jsessio nid=468C8A581361D6E908F97153FEF30398?sequ ence $=1$. Accessed 21 June 2018.

2. International Diabetes Federation. IDF diabetes atlas. 8th ed. 2017. http://www.diabetesatlas.org/ across-the-globe.html. Accessed 21 June 2018.

3. Fehse F, Trautmann M, Holst JJ, Halseth AE, Nanayakkara N, Nielsen LL, Fineman MS, Kim DD, Nauck MA. Xenatide augments first- and secondphase insulin secretion in response to intravenous glucose in subjects with type 2 diabetes. J Clin Endocrinol Metab. 2005;90:5991-7.

4. Weng J, Li Y, Xu W, et al. Effect of intensive insulin therapy on b-cell function and glycaemic control in patients with newly diagnosed type 2 diabetes: a multicentre randomised parallel-group trial. Lancet. 2008;371(9626):1753-60.

5. Li Y, Xu W, Liao Z, et al. Induction of long-term glycemic control in newly diagnosed type 2 diabetic 
patients is associated with improvement of b-cell function. Diabetes Care. 2004;27(11):2597-602.

6. $\mathrm{Hu} \mathrm{Y,} \mathrm{Li} \mathrm{L,} \mathrm{Xu} \mathrm{Y,} \mathrm{et} \mathrm{al.} \mathrm{Short-term} \mathrm{intensive} \mathrm{therapy}$ in newly diagnosed type 2 diabetes partially restores both insulin sensitivity and b-cell function in subjects with long-term remission. Diabetes Care. 2011;34(8):1848-53.

7. Cahn A, Miccoli R, Dardano A, Del Prato S. New forms of insulin and insulin therapies for the treatment of type 2 diabetes. Lancet Diabetes Endocrinol. 2015;3(8):638-52.

8. Meneghini L. New insulin preparations: a primer for the clinician. Cleve Clin J Med. 2016;83(5 Suppl 1):S27-33.

9. Ahlqvist E, Storm P, Käräjämäki A, et al. Novel subgroups of adult-onset diabetes and their association with outcomes: a data-driven cluster analysis of six variables. Lancet Diabetes Endocrinol. 2018;6(5):361-9.

10. American Diabetes Association. Standards of medical care in diabetes-2017: summary of revisions. Diabetes Care. 2017;40(Suppl 1):S4-5.

11. Garber AJ, Abrahamson MJ, Barzilay JI, Blonde L, Bloomgarden ZT, Bush MA, Dagogo-Jack S, DeFronzo RA, Einhorn D, Fonseca VA, Garber JR, Garvey WT, Grunberger G, Handelsman Y, Hirsch IB, Jellinger PS, McGill JB, Mechanick JI, Rosenblit $\mathrm{PD}$, Umpierrez GE. Consensus statement by the American Association of Clinical Endocrinologists and American College of Endocrinology on the comprehensive type 2 diabetes management algorithm-2018 executive summary. Endocr Pract. 2018;24(1):91-120.

12. Silver B, Ramaiya K, Andrew SB, et al. EADSG guidelines: insulin therapy in diabetes. Diabetes Ther. 2018;9(2):449-92.

13. Bajaj S. RSSDI clinical practice recommendations for the management of type 2 diabetes mellitus 2017. Int J Diabetes Dev Ctries. 2018;38(1):1-15.

14. The Society for Endocrinology, Metabolism and Diabetes of South Africa Type 2 Diabetes Guidelines Expert Committee. The 2017 SEMDSA Guideline for the Management of Type 2 Diabetes Guideline Committee. JEMDSA 2017;21 Suppl 1: S1-S196.

15. American Diabetes Association. 8. Pharmacologic approaches to glycemic treatment. Diabetes Care. 2017;40(Suppl 1):S64-74.

16. Inzucchi SE, Bergenstal RM, Buse JB, et al. Management of hyperglycemia in type 2 diabetes, 2015: a patient-centered approach: update to a position statement of the American Diabetes Association and the European Association for the Study of Diabetes. Diabetes Care. 2015;38:140-9.

17. The Royal Australian College of General Practitioners. General practice management of type 2 diabetes: 2016-2018. East Melbourne: RACGP; 2016.

18. Gunton JE, Cheung NW, Davis TME, et al. A new blood glucose management algorithm for type 2 diabetes: a position statement of the Australian Diabetes Society. Med J Aust. 2014;201(11):650-3.

19. Unnikrishnan AG, Tibaldi J, Hadley-Brown M, et al. Practical guidance on intensification of insulin therapy with BIAsp 30: a consensus statement. Int J Clin Pract. 2009;63:1571-7.

20. Wu T, Betty B, Downie M, et al. Practical guidance on the use of premix insulin analogs in initiating, intensifying, or switching insulin regimens in type 2 diabetes. Diabetes Ther. 2015;6:273-87.

21. Mohan V, Kalra S, Kesavadev J, Singh K, Kumar A, Unnikrishnan UG, et al. Consensus on initiation and intensification of premix insulin in type 2 diabetes management. J Assoc Physicians India. 2017;65:59-73.

22. Niskanen L, Leiter LA, Franek E, et al. Comparison of a soluble co-formulation of insulin degludec/insulin aspart vs biphasic insulin aspart 30 in type 2 diabetes: a randomised trial. Eur J Endocrinol. 2012;167:287-94.

23. Kalra S, Latif ZA, Comlekci A, et al. Pragmatic use of insulin degludec/insulin aspart co-formulation: a multinational consensus statement. Indian J Endocrinol Metab. 2016;20(4):542-5.

24. Sheu WH, Ji L, Lee WJ, Jabbar A, Han JH, Lew T. Efficacy and safety of premixed insulin analogs in Asian patients with type 2 diabetes: a systematic review. J Diabetes Investig. 2017;8(4):518-34.

25. Rodbard HW. Therapy progression after basal insulin: GLP-1 agonists vs. prandial insulin vs. premixed insulin. 78th Scientific Sessions. American Diabetes Association. 22-26 June, 2018. Orlando, FL, USA.

26. Downie M, Kilov G, Wong J. Initiation and intensification strategies in type 2 diabetes management: a comparison of basal plus and premix regimens. Diabetes Ther. 2016;7(4):641-57.

27. Giugliano D, Chiodini P, Maiorino MI, Bellastella $\mathrm{G}$, et al. Intensification of insulin therapy with basal-bolus or premixed insulin regimens in type 2 diabetes: a systematic review and meta-analysis of randomized controlled trials. Endocrine. 2016;51:417-28. 
28. Raskin P, Allen E, Hollander P, Lewin A, Gabbay RA, $\mathrm{Hu}$ P, Bode B, Garber A, INITIATE Study Group. Initiating insulin therapy in type 2 Diabetes: a comparison of biphasic and basal insulin analogs. Diabetes Care. 2005;28(2):260-5.

29. Malone JK, Bai S, Campaigne BN, Reviriego J, Augendre-Ferrante B. Twice-daily pre-mixed insulin rather than basal insulin therapy alone results in better overall glycaemic control in patients with Type 2 diabetes. Diabet Med. 2005;22(4):374-81.

30. Strojek K, Bebakar WM, Khutsoane DT, Pesic M, Smahelová A, Thomsen HF, Kalra S. Curr Oncedaily initiation with biphasic insulin aspart 30 versus insulin glargine in patients with type 2 diabetes inadequately controlled with oral drugs: an open-label, multinational RCT. Med Res Opin. 2009;25(12):2887-94.

31. Das AK, Sahay BK, Seshiah V, et al. Indian National Consensus Group: national guidelines on initiation and intensification of insulin therapy with premixed insulin analogs. API India, Medicine Update 2013; Chapter 51:227-236.

32. Kalra S, Gupta Y. Insulin initiation: bringing objectivity to choice. J Diabetes Metab Disord. 2015;14(1):17.

33. Deed G, Kilov G, Dunning T, Cutfield R, Overland J, $\mathrm{Wu} \mathrm{T}$. Use of $50 / 50$ premixed insulin analogs in type 2 diabetes: systematic review and clinical recommendations. Diabetes Ther. 2017;8(6):1265-96.

34. Brod M, Kongsø JH, Lessard S, Christensen TL. Psychological insulin resistance: patient beliefs and implications for diabetes management. Qual Life Res. 2009;18(1):23-32.

35. Khunti K, Wolden ML, Thorsted BL, Andersen M, Davies MJ. Clinical inertia in people with type 2 diabetes: a retrospective cohort study of more than 80,000 people. Diabetes Care. 2013;36(11):3411-7.

36. Indian National Consensus Group. Premix insulin: initiation and continuation guidelines for management of diabetes in primary care. J Assoc Physicians India. 2009;57(Suppl):42-6.

37. Kataoka M, Venn BJ, Williams SM, Te Morenga LA, Heemels IM, Mann JI. Glycaemic responses to glucose and rice in people of Chinese and European ethnicity. Diabet Med. 2013;30(3):e101-7.

38. Kalra S, Atkin S, Cervera A, Das AK, Demir O, Demir $\mathrm{T}$, et al. Multinational consensus: insulin initiation with insulin degludec/aspart (IDegAsp). Adv Ther. 2018;23:1-9.

39. Kalra S, Baruah MP, Sahay R, Kishor K. Pentads and hexads in diabetes care: numbers as targets; numbers as tools. Indian $\mathrm{J}$ Endocrinol Metab. 2017;21(6):794-6.

40. Mitrakou A, Kelley D, Veneman T, Jenssen T, Pangburn T, Reilly J, Gerich J. Contribution of abnormal muscle and liver glucose metabolism to postprandial hyperglycemia in NIDDM. Diabetes. 1990;39:1381-90.

41. Kalra S, Gupta Y. Number-based approach to insulin taxonomy. Diabetes Ther. 2015;6(4):469-79.

42. Wu T. Premixed insulin analogues: a new look at an established option. Diabetes Prim Care Aust. 2016;1:129-33.

43. Kalra S, Plata-Que T, Kumar D, Mumtaz M, Søndergaard F, Kozlovski P, Bebakar WM. Initiation with once-daily BIAsp 30 results in superior outcome compared to insulin glargine in Asians with type 2 diabetes inadequately controlled by oral anti-diabetic drugs. Diabetes Res Clin Pract. 2010;88(3):282-8.

44. Kalra S, Balhara YBS. Insulin distress. US Endocrinol. 2018;14(1):27-9.

45. Kalra S, Gupta Y, Sahay R. The law of therapeutic parsimony. Indian J Endocr Metab. 2016;20:283-4.

46. Monnier L, Lapinski H, Colette C. Contributions of fasting and postprandial plasma glucose increments to the overall diurnal hyperglycemia of type 2 diabetic patients: variations with increasing levels of HbA(1c). Diabetes Care. 2003;26(3):881-5.

47. Wang JS, Tu ST, Lee IT, Lin SD, Lin SY, Su SL, Lee WJ, Sheu WH. Contribution of postprandial glucose to excess hyperglycaemia in Asian type 2 diabetic patients using continuous glucose monitoring. Diabetes Metab Res Rev. 2011;27(1):79-84.

48. Woerle H, Neumann C, Zschau S, Tenner S, Irsigler A, Schirra J, Gerich JE, Göke B. Impact of fasting and postprandial glycemia on overall glycemic control in type 2 diabetes Importance of postprandial glycemia to achieve target HbA1c levels. Diabetes Res Clin Pract. 2007;77(2):280-5.

49. Beisswenger $P$, Heine RJ, Leiter LA, Moses A, Tuomilehto J. Prandial glucose regulation in the glucose triad: emerging evidence and insights. Endocrine. 2004;25(3):195-202.

50. Brito M, Ligthelm RJ, Boemi M, Kumar A, Raz I, Koblik T, Gao Y, Christiansen JS. Intensifying existing premix therapy (BIAsp 30) with BIAsp 50 and BIAsp 70: a consensus statement. Indian J Endocrinol Metab. 2011;15(3):152-60.

51. Su Q, Liu C, Zheng H, Zhu J, Li PF, Qian L, Yang WY. Comparison of insulin lispro mix 25 with 
insulin lispro mix 50 as insulin starter in Chinese patients with type 2 diabetes mellitus (CLASSIFY study): subgroup analysis of a phase 4 open-label randomized trial. J Diabetes. 2017;9(6):575-85.

52. Zafar MI, Ai X, Shafqat RA, Gao F. Effectiveness and safety of Humalog Mix 50/50 versus Humalog Mix $75 / 25$ in Chinese patients with type 2 diabetes. Ther Clin Risk Manag. 2015;11:27-32.
53. Cucinotta D, Smirnova O, Christiansen JS, Kanc K, le Devehat C, Wojciechowska $\mathrm{M}$, de la Torre $\mathrm{M}$ López, Liebl A. Three different premixed combinations of biphasic insulin aspart-comparison of the efficacy and safety in a randomized controlled clinical trial in subjects with type 2 diabetes. Diabetes Obes Metab. 2009;11(7):700-8. 